\title{
O RECOLHIMENTO DE NOSSA SENHORA DA GLÓRIA E AS PERSPECTIVAS DE PROPRIEDADE EM FINS DO SÉCULO XVIII
}

\section{THE RECOLHIMENTO OF NOSSA SENHORA DA GLÓRIA AND THE PERSPECTIVES OF PROPERTY IN ENDS OF CENTURY XVIII}

Mayra Guapindaia*

\begin{abstract}
Resumo: 0 artigo trata das possíveis formas de sustento de uma instituição educativa, o Recolhimento de Nossa Senhora da Glória, na vila do Recife. Nesse sentido, analisa-se a aprovação de um legado de terras deixado às recolhidas por dois eclesiásticos, que serviu para o sustento do Recolhimento após a morte dos doadores. A compreensão da ligação entre o legado e a função educativa da instituição é feita a partir de uma aproximação frutífera com teorias advindas da historiografia sobre propriedade no período moderno.
\end{abstract}

Palavras chave: Gênero, instituições educativas, propriedade

Abstract: The article deals with possible ways of economic support for an women's educational institution in the period of Educational Reforms, the Recolhimento of Nossa Senhora da Glória at the village of Recife. It is approached the approval of a land legacy left to these women by two ecclesiastics. Such legacy would be responsible for support the institution. In order to understand the link between the legacy and the educational function of the institution, it is made an approach with the historiography of property in the modern period.

Keywords: Gender, educational institutions, property.

\section{Introdução}

Este ensaio examina as possíveis formas de sustento de uma instituição que, após 0 período das Reformas Educacionais em Portugal, passou a ganhar feições educativas, mas que não era, contudo, contemplada pelo subsídio literário. Trata-se do Recolhimento de Nossa Senhora da Glória, no Recife, um espaço de clausura feminina. Parte-se do pressuposto de que, apesar desta instituição não ter sido atingida diretamente pela ação do Estado, este buscou condicionar a forma de sustento dessa casa ao ideal pedagógico que se queria colocar em prática à época.

Para cumprir tal objetivo, o ensaio parte de um corpus documental específico: 0 processo que afirmou o Recolhimento como um espaço de educação para mulheres, a partir da aprovação de um legado deixado pelo deão da Sé de Olinda, Antônio Manuel de Carvalho Gondim e seu irmão, o padre Francisco de Araújo de Carvalho Gondim. Levando isso em

\footnotetext{
" Graduada em História pela Universidade de Brasília, no ano de 2009. Atualmente é mestranda pela Universidade de Brasília, na área de História Social, e bolsista do CNPq. Desenvolve pesquisa sobre Gênero e Educação, tendo como objeto de estudo o Recolhimento de Nossa Senhora da Glória nos setecentos.
} 
consideração, parte-se da hipótese de que o reconhecimento do legado por parte da Coroa contribuiu para firmar institucionalmente o projeto do Recolhimento como um espaço educacional.

Há uma estreita ligação, nesse caso específico, entre o projeto educacional reformador da Coroa e os direitos de propriedade que amparam o domínio sobre a terra. Por isso, o aparato teórico desenvolvido pela historiografia de propriedades pode ajudar a compreender como essa instituição se sustentava, e como ela tornou-se uma casa de educação.

Para melhor compreender a ligação dessa casa de clausura feminina com o período das reformas educacionais ilustradas, se faz necessário explicitar brevemente o contexto em questão. A partir de 1772 é dado um novo passo em relação ao conjunto de reformas empreendidas para tentar recuperar Portugal no cenário internacional. Passa-se então a colocar em prática novos ideais e novas formas de educar, montando-se um sistema de ensino sustentado pelo Estado e inspirado nos ideais ilustrados que então circulavam no Reino. 0 intuito das reformas educacionais era formar os futuros administradores públicos¹.

Como se sabe, as reformas pedagógicas não contemplaram de maneira direta as mulheres, e a solução fiscal utilizada para sustentar a educação e construir novas casas educativas - o subsídio literário - só alcançou a formação dos futuros homens públicos que seriam os responsáveis pela administração do reino e das conquistas. Contudo, a reflexão acerca da importância da educação feminina não está ausente do período. No âmbito da llustração Portuguesa, antes mesmo do período de reformas, autores como Luís Antônio Verney e Antônio Nunes Ribeiro Sanches dedicam algum espaço de suas obras sobre a necessidade de mudanças educacionais no reino para discorrer acerca da importância da educação de mulheres. Esses autores ilustrados associavam a importância da educação das mulheres a um fator eminentemente político, uma vez que elas seriam as primeiras mestras dos futuros homens públicos, e deveriam ser preparadas para tal papel. Embalado pelas mesmas idéias, anos mais tarde, D. José Joaquim da Cunha de Azeredo Coutinho, publicou os Estatutos para o Recolhimento de N.S da Glória no mesmo ano em que também publicava os Estatutos para uma

\footnotetext{
1 NEVES, Guilherme Pereira das. O Seminário de Olinda: Educação, cultura e política nos tempos modernos. Dissertação de Mestrado, UFF, 1984, 602; SILVA, Ana Rosa Cloclet da. Inventando a Nação. Intelectuais llustrados e Estadistas Luso-Brasileiros na Crise do Antigo Regime Português (1750-1822). São Paulo: HUCITEC / FAPESP, 2006.
} 
instituição que teria o intuito de formar os futuros homens públicos e de Igreja, o Seminário de Olinda².

Para além das idéias em circulação na época, não se pode deixar de notar que as discussões em relação à educação de mulheres também tiveram funcionamento nas práticas do cotidiano. É possível notar isso a partir do lento processo que levou espaços de clausura, como recolhimentos, a serem afirmados enquanto casas educativas. $O$ objetivo último dessas casas de clausura se tornou, especialmente a partir do século XVIII, era preparar as mulheres para a vida fora do claustro ${ }^{3}$. Nesse sentido, apesar da ausência de apoio formal do Estado português à educação feminina, isso não impediu de se tentar destinar outros espaços, não-oficiais, com 0 intuito de se educar as mulheres.

É no processo de reconhecimento do legado deixado pelos irmãos Gondim por parte da Coroa que se percebe como o Recolhimento passou a ser reconhecido pelo Estado como um espaço educativo, pois, em seus trâmites, encontra-se uma contrapartida para a posse de terras por parte das recolhidas que parece muito peculiar: a Coroa decide que as terras só poderiam ser cedidas para elas caso o recolhimento fosse um espaço aproveitado para a educação de moças.

Portanto, percebe-se que a Coroa se vale da prerrogativa de poder condicionar a concessão de terras para direcionar a renda das propriedades para a sustentação de um projeto educacional. 0 processo de reconhecimento da herança, iniciado após a morte dos irmãos pelo bispo D. José da Cunha de Azeredo Coutinho, perpassa por discussões entre o bispo requerente e a Coroa acerca da legitimidade das terras herdadas. Assim sendo, discussões sobre os fundamentos jurídicos e das práticas sociais que regulamentavam a posse de terras no período são amplamente levantadas pelos dois lados, o que torna esse processo um corpus documental interessante para a compreensão da noção de propriedade fundiária no Antigo Regime.

Este ensaio será dividido em duas partes. Em um primeiro momento, será feita a análise da historiografia acerca das noções de propriedade na modernidade. Em seguida, as categorias utilizadas por essa historiografia serão contrastadas com o processo do Recolhimento da Glória.

\footnotetext{
2 COUTINHO, D. José Joaquim da Cunha Azeredo.1798. Estatuto do recolhimento de Nossa Senhora da Glória do lugar da Boavista de Pernambuco. Lisboa: Tipografia da Academia Real de Ciências, 1798. E Estatutos do Seminário Episcopal de N.Senhora da Graça da Cidade de Olinda de Pernambuco. Lisboa: Tipografia da Academia Real de Ciências, 1798.

${ }^{3}$ ALMEIDA, Suely. O sexo devoto: Normatização e resistência feminina no império português (XVI - XVIII). Recife: Editora Universitária UFPE, 2005.
} 


\section{As noções de propriedade na modernidade: perspectivas historiográficas}

As perspectivas historiográficas acerca da propriedade partem da discussão proveniente do campo interdisciplinar que envolve a história social, econômica e institucional. Especialmente a partir dos anos 1960 e 1970, economistas e historiadores preocupados em estudar as relações de sociedades que não apresentavam uma economia típica de mercado, começaram a desenvolver um aparato teórico apropriado para a compreensão das estruturas dessas sociedades. Dentre os autores que partem dessa perspectiva, se destaca Karl Polanyi ${ }^{4}$ e Giovanni Levi5.

Polanyi parte de uma perspectiva antropológica para a análise das economias de sociedades do Antigo Regime, pois busca levar em consideração a motivação dos indivíduos nas relações econômicas, bem como os aspectos não econômicos que perpassam essas relações. Nesse sentido, Polanyi acredita que a economia é encapsulada (embebbed) em instituições econômicas e não-econômicas. Para o autor, a inclusão do não-econômico na análise, ou seja, aspectos subjetivos e culturais são essenciais para compreender sociedades que não se encaixam no padrão atual de sociedade de mercado. De acordo com o autor o estudo do lugar diverso ocupado pela economia na sociedade é, portanto não mais do que o estudo da maneira como o processo econômico é instituído em diferentes tempos e lugares ${ }^{6}$.

A sociedade de mercado, segundo Polanyi, parte do princípio formal da economia, que acredita que o sistema possui uma série de regras, que na maior parte das vezes condicionam a vontade humana. As regras de mercado são, portanto, auto-reguláveis. Mas deve-se levar em consideração que esses princípios foram instituídos, ou seja, construídos historicamente ao longo do tempo. Sendo assim, cientistas sociais que trabalham com sociedades que não se encaixam no padrão da economia de mercado encontram dificuldades em utilizar o aparato de saber baseado em um sentido formal de economia para entender relações humanas que não se sustentavam nesses padrões.

Já Giovanni Levi, ao trabalhar com o caso específico do Antigo Regime nas sociedades Mediterrâneas, aponta que essas sociedades estavam estruturadas a partir de conceitos jurídicopolíticos como reciprocidade e equidade, o que significava, na prática, que o considerado justo nessas sociedades era dar a cada um o que the era de direito. $O$ direito de possuir, arrendar ou comprar terras, por exemplo, dependia não só do valor em si das posses, mas do valor dos

\footnotetext{
${ }_{4}$ POLANYI, Karl. The economy as instituted process. In: ARENSBERG, C.; PEARSON, H. POLANYI; K. Trade and market in the early empires: economics in history and theory. New York: Free Press, 1976.

${ }^{5}$ LEVI, Giovani. Reciprocidade Mediterrânea. In: ALMEIDA, Carla Maria Carvalho; OLIVEIRA, Mônica Ribeiro de (orgs). Exercícios de Mirco-história. Rio de Janeiro: FGV, 2009.
} 
indivíduos envolvidos nas transações, o que era culturalmente atribuído a partir de uma estrutura hierárquica.

De acordo com esse autor, as transações comerciais e as reivindicações de direitos nessas sociedades seguiam uma lógica própria, que levava em consideração a densa hierarquia social e, consequentemente, o estatuto desigual dos grupos. Nas palavras do autor:

Porém o conceito (de equidade) surgiu e teve importância em sociedades que não reconheciam a igualdade entre cidadãos abstratos - segundo a qual a lei é igual para todos -, mas que, pelo contrário, acentuam a desigualdade de uma sociedade hierárquica e segmentada, em que conviviam sistemas de privilégio e de classificação social: portanto, uma pluralidade de equidades segundo o direito de cara um ao qual se reconheça o que the corresponde sobre a base de sua situação social e de acordo com um princípio de justiça distributivo. Na sociedade de Ancien Régime, o conceito de equidade era o protagonista central de seu sonho impossível (...) de construir uma sociedade justa de desiguais. (...) A lei difere para cada estrato social, quando não para cada pessoa, em uma justiça do caso concreto determinado segundo as desigualdades sociais definidas. ${ }^{\prime \prime}$

Portanto, as relações econômicas mantidas pelos indivíduos nas sociedades de Antigo Regime passam por motivações diferenciadas daquelas que ocorrem em uma economia típica de mercado, a começar pelo fato de que se levava em conta a própria estruturação hierárquica e desigual da sociedade.

Acredita-se que essa perspectiva é fundamental para compreender as relações econômicas na sociedade ibérica moderna, visto que esta pode ser considerada uma sociedade que não funciona de acordo com as regras da sociedade de mercado. Sendo assim, a economia e, conseqüentemente, a noção de propriedade imperante em Portugal na modernidade, devem ser compreendidas a partir de termos diferenciados, sob o risco de a análise tornar-se anacrônica, caso se parta de um ideal liberal ainda inoperante na época.

No caso específico do Recolhimento de Nossa Senhora da Glória, deve-se lembrar que a transação de terras nesse período acontece a partir dessa forma específica de se entender as instituições no Antigo Regime. Sendo assim, a legitimidade do legado deixado às recolhidas dependia de uma série de prerrogativas que levavam em consideração o status social dos grupos envolvidos, bem como a noção de que as propriedades deveriam ser aproveitadas para 0 bem comum.

${ }^{6}$ POLANYI, op.cit., p.250.

7 LEVI, op.cit., p.62 
Um historiador que trabalha com as noções de propriedade levando em consideração as particularidades culturais do mundo ibérico é Antônio Manuel Hespanha ${ }^{8}$ O autor parte do plano das idéias jurídicas para tentar compreender a sociedade portuguesa da época, e, a partir disso, entender a relação entre a sociedade e as noções de domínio e propriedade.

Os trabalhos mais conhecidos de Hespanha são os que discorrem acerca da noção de sociedade corporativa e de bem comum. De acordo com o historiador, Portugal durante 0 período moderno, se organizava na concepção jurídica que via a sociedade como um corpo. Cada parte social tinha sua função específica, sendo que uma parte não poderia desempenhar a função da outra. Sendo assim, a função da cabeça era destinada ao poder real, que era responsável por coordenar as outras partes do corpo. Contudo, a cabeça não poderia desempenhar a função destinada a outras partes. Ao rei, cabia o papel de juiz, buscando arbitrar entre as partes o que era mais necessário ao bem comum e ao bom funcionamento do corpo social. O rei tinha, portanto, um poder preeminente, mas não total 9 .

É a partir da organização político-jurídica do período moderno que Hespanha busca compreender a relação entre poder, terra e domínio. De acordo com o autor, a posse de terra no Antigo Regime português era feita de forma imperfeita. Nesse sentido, a posse de terra era preeminentemente do rei, sendo que esse concedia o domínio a terceiros, com o intuito de tornar a terra produtiva. A posse era, então, limitada com o objetivo de atender ao bem comum.

Segundo o autor, essa premissa começa a ser reformulada a partir do século XVIII, com o surgimento do modelo proprietário. Esse outro modelo prega o domínio perfeito, ou seja, a propriedade plena, e é a base do liberalismo moderno. Contudo, Hespanha acredita que esse modelo só irá se concretizar posteriormente, no século XIX, sendo que a regra no Antigo Regime era o domínio imperfeito: Apesar da ênfase do discurso proprietário, já desde a segunda metade do século XVIII, a sua plena concretização legal data já do século XIX, num momento bastante posterior à revolução liberal ${ }^{10}$.

Obviamente, perceber que os direitos de propriedade no Antigo Regime eram limitados por contrapartidas da Coroa não significa pensar que o Estado tinha poderes ilimitados em relação a essa matéria. Isso faz sentido se levarmos em consideração que a própria noção de

\footnotetext{
8 HESPANHA, António Manuel. As coisas e as situações reais no direito de Antigo Regime.In: 0 direito dos letrados no Império Português. Florianópolis: Fundação Boiteux, 2006.

9 HESPANHA, António Manuel. A constelação originária dos poderes. In: As Vésperas do Leviatã. Coimbra: Almedina, 1994. p.295-380.
}

10 Hespanha, op.cit., p.101 
sociedade corporativa não prevê poderes plenos à cabeça. O rei deveria agir de acordo com os interesses comuns de todo o corpo, e se assim não o fizesse, poderia ser considerado tirano.

Portanto, a posse de terras em Portugal, bem como em seus domínios ultramarinos, está ligada à teoria da sociedade corporativa. O Rei possuía o domínio eminente de todas as terras do reino, sendo que somente o usufruto era cedido para terceiros. Para que houvesse essa cessão, os indivíduos estavam amarrados a uma série de prerrogativas em relação ao aproveitamento da terra. Quando analisa-se a legislação acerca do sistema sesmarial na América Portuguesa, essas prerrogativas ficam evidentes. Sobre o assunto, Costa Porto afirma 0 seguinte:

\begin{abstract}
Não era a terra que o Soberano dava, mas o benefício, o usufruto dela somente. $E$ tanto era assim que, na própria carta de doação, concedia o Rei...um dado prazo de terras ao donatário, (...), o Capitão donatário... era como um locotenente do Rei...exerce direitos de soberania. Só não é proprietário da terra: aufere, apenas, uns tantos proveitos do feudo que lhe foi concedido ${ }^{11}$.
\end{abstract}

A doação de terras no Antigo Regime português era feito a partir do sistema de sesmarias. De acordo com as Ordenações Filipinas, sesmarias eram propriamente as datas de terras, casaes, ou pardieiros, que, foram, ou são de alguns Senhorios, e que já em outro tempo foram lavradas e aproveitadas, e agora não o são ${ }^{12}$. Ou seja, as sesmarias eram terras incultas que eram doadas para terceiros, com o intuito de que se tornassem produtivas. De acordo com Costa Porto, o aproveitamento da terra em prazo determinado era essencial para a manutenção do sistema sesmarial. Ao longo da legislação, também é possível encontrar outras contrapartidas para a posse de terra como, por exemplo, o registro da carta de data, a confirmação desse mesmo registro, o pagamento de dízimo e, a partir de 1699, a imposição do foro.

Ainda segundo Costa Porto, existiam diversos problemas no que diz respeito ao sistema sesmarial na América Portuguesa. Apesar da existência de alguma legislação que buscava regulamentar a posse de terras, a mesma muitas vezes era esparsa e contraditória. Outro problema dizia respeito à fiscalização e ao real cumprimento do que era imposto pela legislação. A extensão das terras da colônia e a distância em relação à metrópole não facilitavam este trabalho. $\mathrm{O}$ autor afirma que somente no final do século XVIII se tem uma tentativa um pouco mais coesa de se regulamentar a questão das sesmarias, a partir da legislação de $1795^{13}$.

\footnotetext{
11 COSTA PORTO, José da. O Sistema Sesmarial no Brasil. Brasília : Unb, 1979, p.21

12 ORDENAÇÕES Filipinas. Livro 4, título XLIII, p.822

13 COSTA PORTO, op.cit
} 
Esse esforço se dá, especificamente, devido a mudança ocorrida na questão da distribuição de terras no século XVIII. Anteriormente, devido à grande extensão de terras, os conflitos por posses não eram tão freqüentes. É a partir do século XVIII, com o aumento populacional, que esses conflitos começam a surgir de maneira mais sistemática. A legislação de 1795 busca organizar a situação e dar uma base legal para a resolução desses conflitos.

É interessante notar essa mudança específica do século XVIII, dando especial atenção à legislação de 1795, uma vez que o processo das recolhidas da Glória se passa entre as décadas de 1780 e 1790. Pode-se enquadrar esse corpus documental a um momento determinado de aumento dos conflitos em relação à terra, e, conseqüentemente, de maior necessidade de garantia de posse, o que se dava a partir da confirmação real. Márcia Mota afirma o seguinte em relação à legislação de 1795 :

\begin{abstract}
É razoável supor que muitos sesmeiros se sentiram constrangidos em cumprir a determinação régia, já que no ano seguinte à promulgação do alvará, no mesmo ano que o revogou, chegaram ao Conselho Ultramarino inúmeras solicitações de tombos de terras, cujo objetivo era medir e demarcar as áreas ocupadas para a consagração de um "título legítimo". Nesse sentido, a despeito da potencial autonomia das câmaras municipais, do poder dos fazendeiros no trato de suas gentes, o fato inconteste é que se reconhecia o papel da Coroa na definição última de quem era o legal ocupante do lugar. (...) Assim sendo, se é verdade que "o poder real partilhava o espaço político de maior ou menor hierarquia, como nos informa Hespanha", a Coroa era a expressão última do poder, pois a ela cabia a chancela, ratificando um domínio ${ }^{14}$.
\end{abstract}

Portanto, em fins do século XVIII, são muitas as cartas enviadas ao Conselho Ultramarino com o intuito de legitimar a posse de terras. A correspondência referente às terras do deão Antônio Manuel de Araújo de Carvalho Gondim e as posteriores cartas de Azeredo Coutinho para que essas mesmas terras fossem reconhecidas legitimamente como posses do Recolhimento da Glória fazem parte desse contexto.

\title{
Posse de terras e educação: o Recolhimento de Nossa Senhora da Glória
}

A primeira informação que aparece na documentação do Arquivo Histórico Ultramarino em relação às posses dos irmãos Gondim é em uma carta de Antônio Manuel Gondim, de 1782, na qual o deão busca mostrar à Coroa que possui bens suficientes para o sustento do Recolhimento. Desde 1780, o mesmo deão se corresponde com o Conselho Ultramarino com 0

14 MOTTA, Márcia Maria M. Poder e domínio: a concessão de sesmarias em fins do Setecentos. In: VAINFAS, R.; MONTEIRO, R.B. (orgs): O Império de várias faces. Relações de poder no mundo ibérico da época moderna. São Paulo: Alameda, 2009, p.352. 
intuito de obter licença para a construção de um recolhimento para donzelas e mulheres necessitadas ${ }^{15}$.

Como os recolhimentos eram espaços leigos, deveriam ter posses o suficiente para se auto-sustentarem. Assim sendo, o Conselho Ultramarino pede informações acerca das formas de sustento do dito recolhimento, ao que responde Manuel Antônio de Carvalho Gondim que o sustento seria proveniente das posses dele e de seu irmão. Buscando mostrar que tinham terras e rendimentos suficientes para o empreendimento, Manuel Antônio faz uma descrição detalhada de suas posses. De acordo com o suplicante:

O dinheiro para se fazer e completar o edifício do recolhimento está pronto, e o temos ajuntado do mesmo rendimento da nossa casa, e seria imprudência intentarmos esta obra sem haver com que a completasse, para não sermos iludidos. 0 maior estabelecimento da nossa casa são duas fazendas de gado vacum e cavalar, que possuímos nos sertões do Norte da Capitania da Paraíba, as quais existem na nossa casa há mais de um século, e são as maiores e mais abundantes daqueles sertões (...) (...)o que rende e produz anualmente 0 gado vacum excede a muito a mil e duzentos bezerros, o gado cavalar a mais de mil bestas, que produzem muitos cavalos. Este presente ano de 1792, desde janeiro até agosto, o rendimento chegou a cinco mil cruzados (...), há alguns anos já que rende menos vinte e quarenta moedas, isto posso afirmar a Vossa Excelência debaixo do juramento aos Santos Evangelhos. Nem faça dúvida que as fazendas de gado podem ter diminuído com as secas, porque as nossas estão fundadas com um território tal, que sendo quase comum a perda do ano de 81 , por faltarem chuvas sete meses, foram as nossas bem livradas porque abundam de olhos d'água ${ }^{16}$.

A descrição feita pelo deão Gondim é expressiva, pois revela a importância atribuída à posse de terras no período em questão. Justamente por possuir terras, segundo sua descrição, ricas, produtivas e abundantes, que o deão poderia dedicar-se à fundação de um recolhimento de mulheres. Nesse sentido, o reconhecimento, por parte da Coroa, de que as terras eram de fato produtivas é essencial para que Antônio Manuel Gondim possa levar adiante seus planos.

A questão da legitimidade das terras também é abordada de outra forma. Gondim faz questão de afirmar que as fazendas existem na nossa casa há mais de um século, buscando assim apontar que as terras foram conseguidas pela família de maneira legítima. Ainda em relação a esse ponto, é interessante notar que Gondim descreve os serviços prestados por seu

${ }^{15} \mathrm{AHU}$ - Avulsos de Pernambuco, cx.146, doc.10658, 1782, fólio 3. 
pai, Manuel Araújo de Carvalho, à Coroa. Mais uma vez, a estratégia nesse caso parece ser provar que a posse das fazendas de gado eram legais, uma vez que foram dadas em sesmaria à Manuel de Araújo Carvalho como recompensa por seus serviços. Nas palavras de Gondim:

(...) atribuindo-se toda esta importância à certíssima consciência de que Deus dotou a meu pai e com muitos serviços que fez à Igreja e a S.Majestade, pois erigiu uma matriz a expensas suas, e domesticou duas nações de índios, com muitos perigos de vida e dispêndio de muitos mil cruzados, pagando quatro anos a missionários e sustentando cinqüenta homens, que mandou o governador da Paraíba João da Maya da gama para auxiliar ao povo por espaço de dois anos ${ }^{17}$.

Segundo Márcia Motta, a estratégia de submissão, ou seja, de se mostrar um vassalo virtuoso que presta distintos serviços à Coroa, é uma forma de garantir o domínio sobre a terra, a partir da mercê real. A autora trata dessa estratégia apontando um caso específico, o de Ignácio Correia Pamplona, e afirma o seguinte:

Em novembro de 1805, o então coronel Ignácio Correia Pamplona pedia mercê por seus distintos serviços. Em dezenas de páginas encaminhadas ao Conselho Ultramarino, Pamplona relatava suas expedições, seus esforços para a destruição dos quilombos e seu percurso como conquistador. Ele expressava assim o emblema do súdito do rei, na expectativa de ver reconhecida sua trajetória de submissão, consolidando seu domínio sobre enormes extensões de terras mineiras ${ }^{18}$.

Assim como Ignácio Pamplona, Manuel de Araújo de Carvalho Gondim busca traçar a trajetória de seu pai como súdito do rei para afirmar o domínio das fazendas de gado. Além das terras propriamente ditas, a carta do deão revela outras posses que serviriam para sustentar 0 recolhimento:

\begin{abstract}
Possuímos mais oito moradas de casas no recife, e mais uma quinta, diante de Olinda três lagoas, que pela frase do país se chama sítio, que é muito grande e produz a nós farinha e todo o legume para uma grande comunidade, não falo a vossa excelência na prata, bens móveis e escravos que possuímos, pois Vossa Excelência só quer saber do estabelecimento para julgar se é prudente a nossa intenção ${ }^{19}$.
\end{abstract}

Ainda na mesma carta, Gondim afirma que tudo o que ele e seu irmão possuem deve ser herdado pelas recolhidas após suas mortes: (...) e tudo quanto possuímos e restarmos inteiramente os deixamos ao tal recolhimento, exceto o que preciso for para o nosso funeral, que

\footnotetext{
${ }^{16} \mathrm{AHU}$ - Avulsos de Pernambuco, cx.146, doc.10658, 1782, fólio 4.

17 AHU; Avulsos de Pernambuco, cx.146, doc.10658, 1782, fólio 4.

18 MOTTA, op.cit., p.358.

${ }^{19} \mathrm{AHU}$ - Avulsos de Pernambuco, cx.146, doc.10658, 1798, fólio 4.
} 
o não queremos pomposo ${ }^{20}$. Portanto, é possível ter uma noção dos bens herdados pelas recolhidas da Glória, mesmo não consultando o testamento de Gondim²1. Chama-se a atenção para o fato de que, além das terras de gado, um sítio e algumas casas no Recife, as recolhidas possivelmente herdaram escravos.

Após anunciar que as recolhidas seriam suas universais herdeiras, o deão prossegue dando informações acerca da administração do recolhimento: Reservamos a administração dos tais bens para nós enquanto vivos formos, e depois da nossa morte, a incumbimos aos prelados dessa diocese ${ }^{22}$. Após a morte dos irmãos, coube ao então bispo de Olinda, D.José Joaquim da Cunha de Azeredo Coutinho, escrever ao Conselho Ultramarino para tentar garantir que as recolhidas recebessem a herança.

As cartas de Azeredo Coutinho também possuem passagens interessantes para compreender as práticas jurídicas e sociais em relação a posse de terras no período em questão23.Mais ainda, é por meio das respostas da Coroa para as súplicas de Azeredo Coutinho é que percebemos a ligação entre a posse de terras e a transformação do recolhimento em uma casa de educação para moças.

Assim sendo, as estratégias utilizadas por Azeredo para garantir a posse de terras do Recolhimento são as mais diversas. O fio condutor da discussão entre Coutinho e o Conselho Ultramarino é a legitimidade da posse de terras por instituições de mão-morta. De acordo com as ordenações filipinas, livro II, título XVIII, as corporações eclesiásticas ou seculares não poderiam possuir bens de raiz sem permissão da Coroa por mais de um ano. Portanto, as recolhidas estavam proibidas de receber as terras a elas deixadas pelos irmãos Gondim, a não ser que obtivessem permissão real.

Azeredo Coutinho traça algumas estratégias para conseguir com que as recolhidas recebam a herança. Uma delas está ligada a afirmação de que todas as contrapartidas necessárias para o domínio das terras serão cumpridas. Como uma das exigências seria justamente o pagamento do dízimo e do foro, o bispo deixa claro que isso será cumprido. Outra questão interessante também é apontada por Azeredo, e diz respeito ao aproveitamento das terras. Ou seja, as terras herdadas seriam produtivas, condição essencial para manter seu domínio. Nas palavras do bispo:

\footnotetext{
20 idem

${ }^{21}$ A única cópia conhecida do testamento de Antonio Manuel de Araújo de Carvalho Gondim se encontra no Arquivo do Convento de Nossa Senhora da Glória. (ver: ALMEIDA, Suely. Op.cit). Infelizmente, não foi possível realizar a consulta desse arquivo até o presente momento para os fins dessa pesquisa.

${ }^{22} \mathrm{AHU}$ - Avulsos de Pernambuco , cx.146, doc.10658, 1798, fólio 4

${ }^{23} \mathrm{AHU}$ - Avulsos de Pernambuco, cx204, doc.13954, anexo 2, 1798.
} 
Alem disso acresce mais que sendo, como são, as terras daquele continente dilatadíssimas, e a maior parte delas incultas, ermas e desertas, e pedindo o maior interesse do Estado que elas se cultivem e, por conseqüência, que se multiplique 0 numero de cultivadores, e dos domínios, seria uma grande ruína, e um gravíssimo prejuízo para os mesmos interesses do Estado, se se restringissem esses domínios e que a cultura das terras daquele continente, se fosse assim retardando mais e mais 24 .

A argumentação do bispo é interessante, pois remete a um discurso frequentemente utilizado por aqueles que buscavam possuir terras na América Portuguesa. A grandeza da terra e a falta de quem a cultive é um argumento normalmente levantado por aqueles que buscavam a doação de sesmarias, e levado em consideração pela Coroa. Vale notar, contudo, que no período em que o bispo recorre à Coroa, a falta de interesse pelas terras ermas e desertas não eram assim tão freqüentes, pois é a partir do século XVIII que as disputas por territórios surgem de forma mais sistemática25. 0 grande problema enfrentado pela Coroa nesse período era a questão da fiscalização, dificultada especialmente pela distância. Afinal, como comprovar se as terras eram realmente incultas?

Ao fim do processo, a Coroa se coloca como favorável às recolhidas, apesar de deixar claro que, segundo a lei, as terras deixadas pelos irmãos Gondim pertenciam ao Erário Régio, e poderiam ser confiscadas caso não se cumprisse as determinações exigidas. Dentre essas determinações, estava o aproveitamento da terra, o pagamento do dízimo e do foro e a necessidade da avaliação e demarcação das terras, assim como o tombamento dos outros bens, no livro do Arquivo da Real Fazenda.

Além das exigências específicas voltada para a doação de sesmarias, encontra-se uma exigência particular, que é a necessidade da casa de clausura se apresentar como um espaço de educação, e não um espaço contemplativo. A Coroa deixa isso bem claro, alegando já existir outras casas responsáveis pelo aspecto religioso:

Todos sabem que em Pernambuco há outro recolhimento de mulheres, como já se notou, sua existência faz dispensável este de que se trata, ao menos para que seja em menor número as recolhidas que nele se houverem de admitir afim, de entrarem no lugar das mais chamadas para o numero, outras tantas educandas pobres, que pela sua indigência e serviço de seus pais mereçam este socorro de educação do qual as não deve privar o infeliz estado de sua pobreza ${ }^{26}$.

${ }^{24}$ AHU - Avulsos de Pernambuco, cx204, doc.13954, anexo 2, 1798, fólio 3.

${ }^{25}$ MOTTA, op.cit.

26 AHU - Avulsos de Pernambuco, cx.204 doc.13954 fólio 6, 1798, anexo 1. Apesar da insistência da Coroa em afirmar que os recolhimentos deveriam ser casas de educação para o século, alguns desses espaços eram cotidianamente utilizados como espaços de vocação religiosa. Por isso, a Coroa chama a atenção para a questão, alertando que o mesmo não deve acontecer como Recolhimento da Glória. Exemplo de uma casa secular que era utilizada como espaço contemplativo era o Recolhimento de Olinda. Vale lembrar, também, que o próprio 
E ainda:

\begin{abstract}
Se este reverendo bispo não tiver se adiantado e conseguido da real e da incomparável grandeza de Vossa Majestade, a mercê de se lhes aprovar os estatutos que ele antecipadamente fez para este recolhimento, havendo já a esse tempo Vossa Majestade sem dúvida adquirido o direito dos bens que são objeto desta consulta, seria muito mais conveniente aos povos, agradável ao público, e útil ao Estado que o seu estabelecimento e estatutos se dirijam somente ao fim de educar meninas pobres, e que para estas se aplicarem aqueles bens, sendo contudo no mesmo recolhimento admitidas todas as maiores porcionistas que os seus pais quisessem mandar educar porque assim utilizava este recolhimento, e ao mesmo passo lucrava o publico recebendo ali umas e outras educandas as sábias lições e dictames do zelo e das virtudes ${ }^{27}$.
\end{abstract}

Deveria ser maior o número de educandas, aquelas que teriam estadia passageira na casa com o intuito de receberem formação, e menor o número de recolhidas, ou seja, aquelas que ficariam enclausuradas durante toda a vida. A educação de moças nas sábias lições e dictames do zelo e das virtudes seria mais útil à sociedade do que um espaço de clausura perpétuo. Assim, a garantia das terras está ligada ao atendimento de uma exigência específica, que é transformar o espaço de clausura em uma casa educativa.

De acordo com Suely Almeida, os recolhimentos eram instituições de clausura que serviam a fins diversos, tanto em Portugal como na América Portuguesa ${ }^{28}$. Tais casas eram procuradas por vários motivos, dentre eles, a falta de um pretendente considerado à altura para as filhas, a necessidade de se castigar a esposa por traição, ou mesmo como um local passageiro, para receber algumas instruções úteis ao casamento e à vida familiar. Essa autora parte do princípio que, apesar das diversas utilizações do espaço de clausura, a Coroa, especialmente a partir do século XVIII, passa a reconhecer essas casas como espaços educacionais e não-contemplativos. Essa seria, portanto, a diferença essencial entre conventos e recolhimentos. Assim, o processo de afirmação do Recolhimento da Glória enquanto espaço educativo deve ser compreendido a partir da conjuntura que transformaram esses espaços de clausura em casas educativas.

\title{
Conclusão
}

O entendimento do processo de reconhecimento do Recolhimento da Glória enquanto um espaço educativo a partir de uma abordagem historiográfica que leve em conta a bibliografia

Recolhimento da Glória surgiu pela ação de mulheres piedosas que decidiram se recolher. Assim, a Coroa está atenta a esses usos cotidianos e tenta condicionar o espaço para fins educativos.

${ }^{27}$ Idem.

${ }^{28}$ ALMEIDA, op.cit. 
acerca das noções de propriedade na modernidade ajudou a propor novas questões ao objeto de pesquisa. Por conseguinte, pode-se perceber como espaços de clausura não abarcados pelo Estado buscavam caminhos para seu auto-sustento. No caso do recolhimento em questão, este auto-sustento veio condicionado a um pré-requisito da Coroa, que era a utilização do espaço para fins educativos. Portanto, mesmo não contando com apoio formal da fazenda real, a Coroa ainda sim se via no direito de opinar acerca do futuro de uma instituição como o Recolhimento da Glória. Nesse caso específico, a Coroa tem essa liberdade devido ao seu domínio eminente em relação às terras, o que garantia a ela o direito de julgar se existiam ou não os requisitos necessários para que as terras fossem doadas em sesmarias para terceiros.

Por outro lado, isso não significa que os indivíduos se submetessem por completo às exigências reais. Como muito bem apontou Márcia Motta (2009), a estratégia de demonstrar submissão muitas vezes era uma forma de garantir o domínio da propriedade. E, ainda mais, muitas vezes as exigências colocadas pela Coroa eram interpretadas de maneiras particulares, 0 que permitia que os indivíduos desviassem da norma.

Não se sabe se esse foi o caso do Recolhimento da Glória. Contudo, parece correto afirmar que D. Azeredo Coutinho se dispõe a cumprir as exigências como uma estratégia para garantir os domínios de terras das recolhidas, uma vez que o bispo escreve os estatutos do recolhimento, demonstrando a clara intenção de transformar a casa em um espaço educativo, posicionando-se a favor da educação feminina de acordo com o papel que as mulheres deveriam representar em sociedade 29 .

$O$ atendimento das ordens da Coroa garantiu não só que a casa se tornasse ao menos pelo que indica seus estatutos, um espaço educativo, mas também garantiu que as recolhidas pudessem possuir terras que garantiriam o sustento da casa. A partir dessa abordagem que leva em consideração as práticas sociais em torno de propriedade e de posse, pode-se perceber como instituições como os recolhimentos buscavam sua legitimação e seu sustento. Para os fins deste ensaio, somente um recolhimento foi analisado. Contudo, acredita-se que tal abordagem pode ser alargada para compreender instituições similares.

Assim, buscou-se evidenciar como instituições educativas que não eram abarcadas pelo subsídio literário se sustentavam, sendo possível notar a presença do Estado nesse processo. Com isso quer dizer-se que, apesar de locais como o Recolhimento da Glória não contarem com o imposto específico para a educação, ainda assim a Coroa tentava condicionar outros meios

${ }^{29}$ COUTINHO, D. José Joaquim da Cunha Azeredo.1798. Estatuto do recolhimento de Nossa Senhora da Glória do lugar da Boavista de Pernambuco. Lisboa: Tipografia da Academia Real de Ciências, 1798, p.2. 
para a sobrevivência desses espaços. Portanto, é possível perceber que a relação entre Estado e educação no século XVIII, o período de reformas educacionais, é muito mais complexo, não se restringindo somente às instituições masculinas que contavam com o suporte econômico do subsídio literário.

\section{REFERÊNCIAS}

\section{Fontes manuscritas}

\section{Fontes do Arquivo Histórico Ultramarino (Projeto Resgate):}

1. AHU - Avulsos de Pernambuco, cx.137. doc.10223, 1780.

2. AHU - Avulsos de Pernambuco, cx.146, doc.10658, 1782.

3. AHU - Avulsos de Pernambuco, cx.149, doc.10821, 1783.

4. AHU - Avulsos de Pernambuco, cx.149, doc.10878, 1783.

5. AHU - Avulsos de Pernambuco, cx.151. doc.10975, 1784.

6. AHU - Avulsos de Pernambuco, cx.204, doc.13954, 1798.

\section{Obras impressas:}

1. COUTINHO, D. José Joaquim da Cunha Azeredo.1798. Estatuto do Recolhimento de Nossa Senhora da Glória do lugar da Boavista de Pernambuco. Lisboa: Tipografia da Academia Real de Ciências, 1798.

2. . Estatutos do Seminário Episcopal de N.Senhora da Graça da Cidade de Olinda de Pernambuco. Lisboa: Tipografia da Academia Real de Ciências, 1798.

3. ORDENAÇÕES Filipinas. Livro 4, título XLIII, p.825-27. Disponível em: <http://www1.ci.uc.pt/ihti/proj/filipinas/> Acesso em: 10/08/2011.

4. SANCHES, Antonio Ribeiro. Cartas sobre a educação da mocidade. Covilhã: Universidade da Beira Interior, 2003 [1 ${ }^{\text {a }}$ Ed.1760].

5. VERNEY, Luis Antonio. Verdadeiro Método de Estudar, 5.vol. Edição organizada por Antonio Salgado Jr. Lisboa: Livraria Sá da Costa, 1950 [1ª Ed.1746].

\section{Referências Bibliográficas}

6. ALMEIDA, Suely. O sexo devoto: Normatização e resistência feminina no império português (XVI - XVIII). Recife: Editora Universitária UFPE, 2005.

7. ACHCRAFT, Richard. Lockean ideas, poverty, and the development of liberal political theory. In: BREWER, J.; STAVES, S.; Early modern conceptions od property. New York, London: Routledge, 1996.

8. COSTA PORTO, José da. O Sistema Sesmarial no Brasil. Brasília : Unb, 1979, p.21 
9. FONSECA, Thais Nivia de Lima e. Sociabilidades e estratégias educativas numa sociedade mestiça (Minas Gerais, Brasil, século XVIII). In: Congresso Internacional o Espaço Atlântico de Antigo Regime: poderes e sociedades, Lisboa: 2005, v. 1. Pp. 5252.

10. Historiografia da educação da América Portuguesa: balanço e perspectivas. Revista Lusófona de Educação, 2009, V.14, pp.111-124.

11. FRANCO, Maria Sylvia C. All the world was America. John Locke, liberalismo e propriedade como conceito antropológico. Revista da USP. Dossiê liberalismo/neoliberalismo, v.17, 30-53, 1993.

12. HESPANHA, António Manuel. A constelação originária dos poderes. In: As Vésperas do Leviatã. Coimbra: Almedina, 1994. P.295-380.

13. As coisas e as situações reais no direito de Antigo Regime.In: 0 direito dos letrados no Império Português. Florianópolis: Fundação Boiteux, 2006.

14. LEVI, Giovani. Reciprocidade Mediterrânea. In: ALMEIDA, Carla Maria Carvalho; OLIVEIRA, Mônica Ribeiro de (orgs). Exercícios de Mirco-história. Rio de Janeiro: FGV, 2009.

15. MARAVALL, José Antonio. A fundação do direito privado como limite do poder do Estado. In: HESPANHA, A.M.: Poder e instituições na Europa do Antigo Regime. Lisboa: Fundação Caloustre Gulbenkian, 1984.

16. MOTTA, Márcia Maria M. Poder e domínio: a concessão de sesmarias em fins do Setecentos. In: VAINFAS, R.; MONTEIRO, R.B. (orgs): O Império de várias faces. Relações de poder no mundo ibérico da época moderna. São Paulo: Alameda, 2009.

17. NEVES, Guilherme Pereira das. O Seminário de Olinda: Educação, cultura e política nos tempos modernos. Dissertação de Mestrado, UFF, 1984, 602p.

18. POLANYI, Karl. The economy as instituted process. In: ARENSBERG, C.; PEARSON, H. POLANYI; K. Trade and market in the early empires: economics in history and theory. New York: Free Press, 1976.

19. RIBEIRO, Arilda Ines Miranda. Vestígios da Educação Feminina no século XVIII em Portugal. Arte e Ciência: São Paulo, 2002.

20. SCOTT, Joan W. Gender: A Useful Category of Historical Analysis. The American Historical Review, Vol. 91, No. 5 (Dec., 1986), pp. 1053-1075.

21. SILVA, Ana Rosa Cloclet da. Inventando a Nação. Intelectuais llustrados e Estadistas Luso-Brasileiros na Crise do Antigo Regime Português (1750-1822). São Paulo: HUCITEC / FAPESP, 2006. 
22. SILVA, Maria Beatriz Nizza. Educação feminina e educação masculina no Brasil colonial. Revista de História.São Paulo: USP, n.109, 1977, v.55. pp149-164.

23. SILVA, Adriana Maria Paulo da. Processos de construção das práticas de escolarização em Pernambuco, em fins do século XVIII e primeira metade do século XIX. UFPE: Recife, 2007.

Artigo recebido em: 01/10/2011

Aprovado para publicação em 31/10/2011 